\title{
Management and prognostic markers in patients with autoimmune encephalitis requiring ICU treatment
}

\begin{abstract}
Julia Schubert, MD, Dirk Brämer, MD, Hagen B. Huttner, MD, Stefan T. Gerner, MD, Hannah Fuhrer, MD, Nico Melzer, MD, Andre Dik, MD, Harald Prüss, MD, Lam-Than Ly, MD, Kornelius Fuchs, MD,

Frank Leypoldt, MD, Gunnar Nissen, MD, Ingo Schirotzek, MD, Christian Dohmen, MD, Julian Bösel, MD, Jan Lewerenz, MD, Franziska Thaler, MD, Andrea Kraft, MD, Aleksandra Juranek, MD, Marius Ringelstein, MD, Kurt-Wolfram Sühs, MD, Christian Urbanek, MD, André Scherag, PhD, Christian Geis, MD, Otto W. Witte, MD, and Albrecht Günther, MD, for the GENERATE and IGNITE network
\end{abstract}

Neurol Neuroimmunol Neuroinflamm 2019;6:e514. doi:10.1212/NXI.0000000000000514

\section{Abstract}

\section{Objective}

To assess intensive care unit (ICU) complications, their management, and prognostic factors associated with outcomes in a cohort of patients with autoimmune encephalitis (AE).

\section{Methods}

This study was an observational multicenter registry of consecutively included patients diagnosed with AE requiring Neuro-ICU treatment between 2004 and 2016 from 18 tertiary hospitals. Logistic regression models explored the influence of complications, their management, and diagnostic findings on the dichotomized (0-3 vs 4-6) modified Rankin Scale score at hospital discharge.

\section{Results}

Of 120 patients with $\mathrm{AE}$ (median age 43 years [interquartile range 24-62]; 70 females), 101 developed disorders of consciousness, 54 autonomic disturbances, 42 status epilepticus, and 39 severe sepsis. Sixty-eight patients were mechanically ventilated, 85 patients had detectable neuronal autoantibodies, and 35 patients were seronegative. Worse neurologic outcome at hospital discharge was associated with necessity of mechanical ventilation (sex- and age-adjusted OR 6.28; 95\% CI, 2.71-15.61) tracheostomy (adjusted OR 6.26; 95\% CI, 2.68-15.73), tumor (adjusted OR 3.73; 95\% CI, 1.35-11.57), sepsis (adjusted OR 4.54; 95\% CI, 1.99-10.43), or autonomic dysfunction (adjusted OR 2.91; 95\% CI, 1.24-7.3). No significant association was observed with autoantibody type, inflammatory changes in CSF, or pathologic MRI.

\section{Conclusion}

In patients with $\mathrm{AE}$, mechanical ventilation, sepsis, and autonomic dysregulation appear to indicate longer or incomplete convalescence. Classic ICU complications better serve as prognostic markers than the individual subtype of AE. Increased awareness and effective management of these AE-related complications are warranted, and further prospective studies are needed to confirm our findings and to develop specific strategies for outcome improvement.

\author{
Correspondence \\ Dr. Günther \\ Albrecht.guenther@med.uni-jena.de
} From the Hans-Berger-Department of Neurology (J.S., D.B., C.G., O.W.W., A.G.), Jena University Hospital; Department of Neurology (H.B.H., S.T.G.), University Hospital Erlangen;
Department of Neurology and Neurophysiology (H.F), University Hospital Freiburg; Department of Neurology (N.M., A.D.), University Hospital Münster; Department of Neurology
(H.P., L.-T.L), Charité University Medicine Berlin; Department of Neurology (K.F.), Bezirksklinikum Regensburg; Neuroimmunology Section (F.L., G.N.), Institute of Clinical Chemistry and
Department of Neurology, University Hospital Schleswig-Holstein, Kiel; Department of Neurology (I.S.), University Hospital Giessen; Center for Neurology and Psychiatrics (C.D.),
University Hospital Köln; Department of Neurology (.B.), University Hospital Heidelberg; Department of Neurology (J.B.), Klinikum Kassel; Department of Neurology (.L.), University
Hospital Ulm; Institute of Clinical Neuroimmunology (F.T.), Ludwig-Maximillians-University München; Department of Neurology (A.K.), Martha Maria Hospital Halle; Department of
Neurology (A.J.), Dortmund Hospital; Department of Neurology (M.R.), Medical Faculty, Heinrich Heine University Düsseldorf; Department of Neurology (K.-W.S.), University Hospital
Hannover; Department of Neurology (C.U.), Hospital Ludwigshafen; Institute of Medical Statistics, Computer and Data Sciences (A.S), Jena University Hospital; and Center for Sepsis
Control and Care (A.S., C.G.), Jena University Hospital, Germany.
Funding information and disclosures are provided at the end of the article. Full disclosure form information provided by the authors is available with the full text of this article at Neurology.org/NN. 


\section{Glossary}

$\mathrm{AE}=$ autoimmune encephalitis; $\mathbf{A E D}=$ antiepileptic drug; $\mathbf{D W I}=$ diffusion-weighted imaging; $\mathrm{eCRF}=$ electronic case report form; FDG-PET = fluorodeoxyglucose PET; FLAIR = fluid-attenuated inversion recovery; GENERATE = German Network for Research in Autoimmune Encephalitis; ICU = intensive care unit; IGNITE = Initiative of German Neurointensive Trial Engagement; $\mathbf{I Q R}=$ interquartile range; $\mathbf{m R S}=$ modified Rankin Scale; $\mathbf{R E}=$ receptor encephalitis; $\mathbf{S E}=$ status epilepticus.

Autoimmune encephalitis (AE) is a potentially life-threatening inflammation of the CNS and constitutes $20 \%-30 \%$ of encephalitis cases in adults. ${ }^{1} \mathrm{AE}$ often leads to subacute, severe, and debilitating encephalitis necessitating long-term management in a neurologic intensive care unit (ICU). Recent estimations on mortality due to AE range between $12 \%$ and $40 \%,{ }^{2-4}$ although only limited data are available on in-hospital mortality and morbidity. Patients with AE-associated anti-NMDA receptor antibodies in particular, ${ }^{5}$ but also those with $\mathrm{AE}$ associated with antibodies against other neuronal surface or intracellular antigens, often require long-term ICU management. ${ }^{4}$ Moreover, more than $40 \%$ of patients with probable $\mathrm{AE}$ without antineuronal antibody detection and exclusion of other disorders require ICU treatment. ${ }^{2}$ In turn, long-term ICU treatment together with immunosuppression as mandatory therapy puts these patients at high risk of ICU treatmentrelated complications. Neurologic ICU complications due to $\mathrm{AE},{ }^{6}$ such as status epilepticus, severe hyperkinetic movement, and autonomic disorders, are usually dealt with on a case-bycase basis. In fact, there are limited data available on the frequency, management, and potential prognostic value of complications in the ICU for patients with AE. ${ }^{7}$

The ICU-CompoSE study (ICU-Complications of Severe Encephalitis) focuses on demographic and clinical characteristics in a large cohort of AE patients' subtypes requiring neuro-ICU treatment. In the study, we aimed at identifying ICU-specific prognostic factors. In addition, we assessed potential factors for short-term outcome on discharge from hospital instead of long-term outcome, which reflects other factors of individual AE subtypes, e.g., relapse frequency and tumor association. Moreover, we also assessed potential prognostic factors for worse outcome at discharge from hospital.

We hypothesize that short-term outcome of patients with $\mathrm{AE}$ requiring ICU treatment is dependent on the occurrence of ICU complications rather than on diagnostic subtypes of AE.

\section{Methods}

\section{Design and patients}

We conducted a multicenter nationwide cohort study in 18 tertiary neurologic centers in Germany and consecutively included patients between January 1, 2004, and December 31, 2016. The cooperation of 2 German neurologic and neurointensive care networks (German Network for Research in Autoimmune Encephalitis [GENERATE], generate-net.de, and Initiative of German Neurointensive Trial Engagement [IGNITE], dgni.de/forschung/ignite-initiative-klinischer- multizenter-studien/ueber-ignite.html) facilitated compiling information in the GENERATE databank on patients with the clinical syndrome of $\mathrm{AE}$ requiring intensive care treatment.

The inclusion criteria for patients were as follows: patients of any age with the clinical syndrome of encephalopathy including disturbance of consciousness for more than 24 hours with accompanying lethargy, irritability, and any change in personality or behavior ${ }^{1}$ were included in this study if at least 2 of the following criteria were met: (1) fever or history of fever, (2) epileptic seizures and/or new neurologic deficits, (3) CSF pleocytosis (>4 cells/ $\mu \mathrm{l})$, (4) EEG abnormalities, and (5) pathologic neuroimaging findings (MRI/CT). Furthermore, infectious or other alternative causes of encephalopathic syndrome had to be excluded. In addition, only patients admitted to an ICU during the course of the disease were included. ICU admission was necessary if the patient had one or more of the following symptoms: decreased level of consciousness, severe dyskinesia, autonomic dysfunction, epileptic seizure(s)/status epilepticus, and need for mechanical ventilation or other complications, such as severe sepsis, thrombosis, embolic events, other relevant organ failure, cardiac arrhythmia, resuscitation, and increased intracranial pressure.

\section{Standard protocol approvals, registration, and patient consents}

The study protocol was approved by the local research ethics committee at each center. Written informed consent was obtained from every patient or their representative.

\section{Data collection}

Data were collected at the participating GENERATE and IGNITE centers on the basis of cooperation within the network. At each collaborating center, a local investigator retrospectively gathered demographic information (sex, age, ethnic background, and patient's medical history) and all clinical AE features (prodromi, symptoms at presentation, and onset and duration dates). In addition, ICU charts were used to retrieve patient data on the management of ICU complications. Major complications and their therapeutic management during the patient's stay in the ICU and patient's clinical outcome were documented using an electronic case report form (ICUCompoSE-eCRF) extending the existing GENERATE-eCRF.

The major clinical ICU problems consisted of the following:

1. Disturbance of consciousness: coma duration and onset in course of the disease, somnolence, sopor, mutism, and delirium; 
2. Autonomic dysfunction: hyperthermia, hypoventilation/ hyperventilation, tachycardia/bradycardia, cardiac arrhythmia, cardiac arrest, hypotensive/hypertensive arterial blood pressure, diarrhea, hyperhidrosis, and sialorrhea;

3. Status epilepticus (SE)/seizures: semiology (if available), duration and frequency of seizures/status, refractory status, detection of SE, use of EEG monitoring, and antiepileptic drugs (AEDs) used;

4. Movement disorder and hyperkinetic status: clinical manifestation, management, and drugs used;

5. Other complications: severe sepsis/septic shock, other relevant organ failure, increase in intracranial pressure, resuscitation, surgical complications, and psychiatric complications (e.g., suicide attempt);

6. Ethical conflicts: ovarectomy (prophylactic or diagnostic), change in therapeutic goal, therapy limitation or disruption, and interdisciplinary ethical consultation.

Additional systematically assessed data included the following:

1. Mechanical ventilation: reason for intubation, time of intubation during the course of the disease, duration of ventilation, ventilation mode, time and reason for tracheostomy, reintubation, and other ventilatory problems;

2. Algesia and sedation: duration, drugs used, and use of inhalative sedation (isoflurane and sevoflurane).

Diagnostic workup data included laboratory testing for autoantibodies from CSF and serum, neurophysiologic data (i.e., EEG results), and brain imaging results (pathologic MRI suggestive for $\mathrm{AE}$ was defined as a hyperintense signal on $\mathrm{T} 2$ weighted fluid-attenuated inversion recovery (FLAIR) sequences highly restricted to one or both medial temporal lobes or in multifocal areas involving gray matter, white matter, or both compatible with demyelination or inflammation). ${ }^{8}$ If available, cerebral fluorodeoxyglucose PET (FDG-PET) results were also retrieved. Furthermore, in case a tumor had been detected, the entity of the tumor and antitumor therapy were retrieved.

For outcome analysis, values of the modified Rankin Scale (mRS) were retrieved by the treating physician from clinical charts during the ICU stay, revealing both the poorest value (maximum mRS-obtained at the poorest neurologic/ functional status of the patient) and the mRS at the end of the hospital stay. Good neurologic outcome was defined as a dichotomized (mRS) score of $0-3$ for no disability to moderate disability at hospital discharge, whereas mRS scores of 4-6 were defined as poor outcome. ${ }^{9}$

\section{Statistical analyses}

Descriptive statistics summarize the patient's characteristics (continuous variables: quartiles/count data: absolute and relative frequencies). Because we had to work with the given sample of this rare disease, we performed no formal sample size calculations. Consequently, we limited the modeling, avoided data imputations, did not examine subgroups or interactions, and did not strictly control the type I error rate; results are explorative. We performed crude and adjusted logistic regressions (adjusted for age [linear and per year] and sex) to derive factors associated with good to moderate ( $\mathrm{mRS}$ scores $0-3$ ) or poor (mRS scores 4-6) neurologic outcome at hospital discharge. Because linear regression models with untransformed $\mathrm{mRS}$ scores lead to the same conclusions, we decided to focus on the logistic regression results. In total, we explored 19 potential prognostic factors. In light of only 7 observed in-hospital deaths, we decided not to run additional regression models for hospital mortality. We report crude and adjusted ORs with 2-sided 95\% CIs (not corrected for multiplicity) and a significance level $\alpha=0.05$ (2-sided). All statistical analyses were performed using the statistical language $\mathrm{R}$ 3.4.3. (Source: $\mathrm{R}$ Core Team [2014]. R: A language and environment for statistical computing. R Foundation for Statistical Computing, Vienna, Austria. URL R-project.org/).

\section{Data availability statement}

The data used for this study can be supplied by the corresponding author upon request. The STROBE guidelines were used for reporting of this observational study.

\section{Results}

\section{Patient characteristics}

Of the 602 patients enrolled in the GENERATE database (until December 31, 2016), we included 120 patients in the ICU-CompoSE study. The median age at disease onset was 43 years (interquartile range [IQR] 24-62, range 9-82 years), and 70 patients $(58 \%)$ were female (table 1$)$. Ethnicity was Caucasian in $99 \%$ and Asian in $1 \%$.

Clinically, consistent with the accounts of the treating physicians and the clinical charts, $63 \%$ of the 120 patients showed symptoms of limbic encephalitis, whereas $31 \%$ were judged to show a generalized form of encephalitis, and $8 \%$ exhibited brain stem encephalitis. Other specific clinical syndromes included cerebellitis and Rasmussen encephalitis (table 1).

Prodromal symptoms were found in $34 \%$, and the median duration of these symptoms was 8 days (IQR: 5-34; range 1-1,000 days). Prodromal symptoms consisted of unspecific respiratory or gastrointestinal symptoms $(50 \%)$, headache (47\%), neurologic deficits (41\%), psychiatric symptoms (26\%), and cognitive impairment (15\%). The median delay between first symptoms and hospital admission was 6 days (IQR: 0-32; range 0-3,485 days).

MRI was performed in $98 \%$ of patients, and a pathologic result was obtained in $70 \%$. In detail, the main pathologic findings consisted of FLAIR lesions $(\mathrm{N}=88)$, diffusion-weighted imaging lesions $(\mathrm{N}=25)$, MRI-contrast enhancing lesions ( $\mathrm{N}$ $=15)$, and limbic lesions $(\mathrm{N}=52)$.

EEG showed pathologic findings in $84 \%$ (generalized slow activity in $85 \%$, focal abnormalities in $60 \%$, and epileptic discharges in $41 \%$ of patients). 
Table 1 Demographic and clinical characteristics and diagnostic workup of the ICU-CompoSE cohort

\begin{tabular}{ll}
\hline Variable & All $\mathbf{n}=\mathbf{1 2 0}$ \\
\hline Age, median (min/max), $\mathbf{y}$ & $43(9 / 82)$ \\
\hline IQR & $24 / 62$ \\
\hline Female sex (\%) & $70(58)$ \\
\hline Prodromi, number of patients (\% of $\mathbf{n}=\mathbf{1 2 0})$ & $41(34)$ \\
\hline Duration of prodromi median (min/max), d & $8(1 / 1,000)$ \\
\hline IQR, & $5 / 34$ \\
\hline
\end{tabular}

Clinical syndrome ${ }^{\mathrm{a}}$, number of patients

\begin{tabular}{ll}
\hline Limbic encephalitis & 76 \\
\hline Encephalitis & 37 \\
\hline Movement disorder & 9 \\
\hline Encephalomyelitis & 4 \\
\hline Rasmussen encephalitis & 3 \\
\hline Brainstem encephalitis & 2 \\
\hline Cerebellitis & 2 \\
\hline Focal encephalitis & 2 \\
\hline Progressive encephalomyelitis with rigidity \\
and myoclonus & 1 \\
\hline Unknown & 1
\end{tabular}

Diagnostic results, number of patients (\%)

\begin{tabular}{ll}
\hline CSF $(\mathbf{n}=\mathbf{1 1 6})$ & \\
\hline Pleocytosis $(\%$, total $\mathbf{n}=\mathbf{1 1 6})$ & $70(60)$ \\
\hline Elevated CSF protein level $(\%$, total $\mathbf{n}=\mathbf{1 1 6})$ & $50(43)$ \\
\hline Oligoclonal bands (OCBs) tested $(\%$ of $\mathbf{n}=\mathbf{1 1 6})$ & $89(77)$ \\
\hline OCB-positive CSF (\% of $\mathbf{n}=\mathbf{8 9})$ & $26(29)$ \\
\hline OCB-positive CSF and serum $(\%$ of $\mathbf{n}=\mathbf{8 9})$ & $25(28)$ \\
\hline OCB negative (\% of $\mathbf{n}=\mathbf{8 9})$ & $38(42)$ \\
\hline MRI, number of patients $(\%$ of $\mathbf{n}=\mathbf{1 2 0})$ & $118(98)$ \\
\hline Pathologic & $83(70)$ \\
\hline Brain PET, number of patients (\% of $\mathbf{n}=\mathbf{1 2 0})$ & $51(43)$ \\
\hline Pathologic & $32(63)$ \\
\hline EEG, number of patients $(\%$ of $\mathbf{n}=\mathbf{1 2 0})$ & $107(89)$ \\
\hline Pathologic & $90(84)$ \\
\hline Tumor screening, number of patients $(\%$ of $\mathbf{n}=\mathbf{1 2 0})$ & $112(93)$ \\
\hline Diagnosis of tumor ${ }^{\mathbf{b}}$ & $25(21)$ \\
\hline Autoantibody (AAB) detection, number of patients $(\%)$ & $120(100)$ \\
\hline Serum tested & $110(92)$ \\
\hline CSF tested & $93(76)$ \\
\hline AAB found & $851)$ \\
\hline
\end{tabular}

Table 1 Demographic and clinical characteristics and diagnostic workup of the ICU-CompoSE cohort (continued)

\begin{tabular}{ll}
\hline Variable & All $\mathbf{n}=\mathbf{1 2 0}$ \\
\hline AAB found CSF & $57(48)$ \\
\hline AAB found serum & $68(57)$ \\
\hline AAB group ${ }^{\text {a }} \%$ of $\left.\boldsymbol{n}=\mathbf{8 5}\right)$ & $53(62)$ \\
\hline NMDA & $10(12)$ \\
\hline VGKC (4Lgl1,2 CASPR2, 4VGKC) & $5(6)$ \\
\hline GAD & $4(5)$ \\
\hline GABA & $4(5)$ \\
\hline Paraneoplastic (anti-Hu, anti-Yo) & $12(14)$ \\
\hline Others & \\
\hline Ovarectomy, number of patients (\% of $\mathbf{n}=\mathbf{1 2 0})$ & $10(8)$ \\
\hline Monolateral & $4(3)$ \\
\hline Bilateral & $3(3)$ \\
\hline Explorative ovarectomy & $3(3)$ \\
\hline Incomplete removal & $5(4)$ \\
\hline Oocyte removal & $1(1)$ \\
\hline
\end{tabular}

Abbreviations: VGKC $=$ voltage-gated potassium channel complex, $\mathrm{LgI}=$ leucine-rich glioma inactivated 1, CAPSR2 = contactin-associated protein 2 , $\mathrm{GABA}=$ gamma-aminobutyric acid, $\mathrm{GAD}=$ glutamic acid decarboxylase; $\mathrm{OCB}$ = oligoclonal band.

${ }^{a}$ Multiple selection possible.

b Tumor entity: 10 teratoma, 6 bronchial carcinoma, 1 lymphoma, rectal carcinoma, breast carcinoma, prostate carcinoma, seminoma (each), 1 undifferentiated unclassified tumor, and 3 undetermined tumors.

'Amphiphysin $(n=1)$, Glycine $(n=2)$, MAK (male germ cell-associated kinase) ( $n=1)$, ITPR1 (inositol triphosphate receptor) $(n=1)$, SOX (Sry-like motility group box) $(n=1)$, AAB against potassium channels $(n=3)$, not further specified $(n=3)$.

CSF was analyzed in $97 \%$ of the patients; $60 \%$ had pleocytosis, and $50 \%$ showed an increased total protein content. Isolated oligoclonal bands in CSF were seen in $29 \%$.

Neuronal autoantibodies were examined in $27 / 120$ patients in serum only, $10 / 120$ patients in CSF only, and 83/120 patients in CSF and serum. Autoantibody testing was performed by commercially available mosaic biochip (Euroimmun, Lübeck, Germany) according to the manufacturer's procedures by certified laboratories and by scientific laboratories using immunohistochemistry. ${ }^{10}$ Well-characterized neuronal autoantibodies were detected in $85 / 120$ patients ( $71 \%$ total, $57 \%$ in serum, $48 \%$ in CSF, and $47 \%$ both). Anti-NMDA-R antibodies were most common, followed by leucine-rich gliomainactivated 1, CASPR2, and glutamic acid decarboxylase (table 1). A total of $93 \%$ of patients were screened for a tumor, which was found in $21 \%$ of the screened patients (table 1 ).

\section{ICU complications and management}

Eighty-four percent of patients had a decreased level of consciousness, and 34\% developed delirium. Impairment of 
consciousness lasted more than 8 days in $70 \%$ and more than 30 days in $32 \%$ of patients.

Autonomic dysregulation (33\% tachycardia, 19\% bradycardia, $18 \%$ hypertensive crisis or hypotension, $18 \%$ hypoventilation, and $13 \%$ hyperthermia) was seen in $45 \%$ of patients. The therapeutic strategies including external and internal cooling and administration of IV dantrolene for fever treatment, pacemaker for bradycardia, mechanical ventilation for hypoventilation, and catecholamines/antihypertensives for blood pressure dysregulation are listed in table 2.

Thirty-five percent of patients developed status epilepticus (SE) (43\% generalized, 37\% nonconvulsive, and 34\% focal or complex-focal), and $34 \%$ of patients had a relapse SE. The duration of SE was less than 1 day in $36 \%$ and more than 7 days in $28 \%$ of patients. The median number of different AEDs per patient with SE used to treat epileptic status was 5 .

Thirty-three percent of patients showed movement disorders, which were treated with benzodiazepines (74\%), AEDs (53\%), and propofol (31\%). We cannot exclude that some of the movement disorders were actually epileptic events and vice versa, especially without EEG.

Other relevant complications: $26 \%$ of patients experienced severe sepsis with organ dysfunction and $7 \%$ septic shock. Ten percent underwent cardiopulmonary resuscitation. Eight percent had venous thrombosis.

Mechanical ventilation was necessary in $57 \%$ of all patients, with a median duration of 28 days (IQR: 10-54; range 1-350 days). Thirty-seven percent had to be reintubated, and $68 \%$ underwent tracheostomy during the course of ICU treatment. Fifty-four percent of the patients developed ventilatorassociated pneumonia (Table 3).

\section{Outcome and potential prognostic factors}

The median duration of ICU stay was 24 days (IQR: 7-45), and the median duration of hospital stay was 49 days (IQR: 31-100). Ninety percent of patients showed a maximum mRS score of $\geq 4$ ( $23 \% \mathrm{mRS}$ score $4,61 \% \mathrm{mRS}$ score 5 , and $7 \%$ mRS score 6). At the time of hospital discharge, $47 \%$ of patients showed a mRS score of $\geq 4(28 \% \mathrm{mRS}$ score $4,15 \%$ mRS score 5 , and $7.5 \%$ mRS score 6$)$. However, 60 patients (50\% of the total cohort) had improved mRS values compared with the maximum mRS value [mRS 1 (12 patients), 2 (21 patients), and 3 (27 patients)] (figure).

Fifty-five percent of patients were discharged from the ICU to regular hospital wards, and $38 \%$ were transferred to neurologic intensive care rehabilitation centers. In $18 \%$ of cases, an ethical conflict had to be resolved during the hospital stay.

Table 4 summarizes the results of the crude and the sex- and age-adjusted logistic regression analyses. Of the 19 potential
Table 2 AE-associated complications and clinical management

\begin{tabular}{ll}
\hline Variable & $\begin{array}{l}\text { All } \\
\mathbf{n}=\mathbf{1 2 0}\end{array}$ \\
\hline Consciousness disorder, no. of patients $(\%$ of $\mathbf{n}=\mathbf{1 2 0})$ & $101(84)$ \\
\hline Manifestation & \\
\hline Somnolence & $40(33)$ \\
\hline Sopor & $30(25)$ \\
\hline Coma & $18(15)$ \\
\hline Delirium & $41(34)$ \\
\hline Mutism & $13(11)$ \\
\hline
\end{tabular}

Duration of consciousness disorder

\begin{tabular}{ll}
\hline Median, d (IQR) & $20(5-40)$ \\
\hline Minimum/maximum, d & $0-400$ \\
\hline $\mathbf{1} \mathbf{d}$ & 7 \\
\hline $\mathbf{1 - 7} \mathbf{d}$ & 22 \\
\hline $\mathbf{8 - 3 0} \mathbf{d}$ & 28 \\
\hline$>\mathbf{3 0} \mathbf{d}$ & 32 \\
\hline Autonomic disorders, no. of patients (\% of $\mathbf{n = 1 2 0})$ & $54(45)$ \\
\hline Manifestation & $15(13)$ \\
\hline Fever without infection & $22(18)$ \\
\hline Hypoventilation & $12(10)$ \\
\hline Hyperventilation & $40(33)$ \\
\hline Tachycardia & $23(19)$ \\
\hline Bradycardia & $11(9)$ \\
\hline Other heart rhythm disorders & $21(18)$ \\
\hline Blood pressure crises & $6(5)$ \\
\hline Diarrhea & $10(8)$ \\
\hline Hypersalivation &
\end{tabular}

Therapy, no. of patients

\begin{tabular}{ll}
\hline Dantrolene & 3 \\
\hline External cooling & 12 \\
\hline Internal cooling & 7 \\
\hline Pacemaker & 11 \\
\hline Status epilepticus (SE), no. of patients (\% of $\mathbf{n = 1 2 0 )}$ & $42(35)$ \\
\hline Manifestation (\% of $\mathbf{n}=\mathbf{4 2})$ & \\
\hline Generalized SE & $18(43)$ \\
\hline Focal SE & $14(33)$ \\
\hline Nonconvulsive SE & $15(36)$ \\
\hline SE relapse & $13(31)$ \\
\hline
\end{tabular}


Table 2 AE-associated complications and clinical management (continued)

\begin{tabular}{lc}
\hline Variable & $\begin{array}{l}\text { All } \\
\mathbf{n}=\mathbf{1 2 0}\end{array}$ \\
\hline \multicolumn{1}{l}{ Cumulative duration of SE no. of patients (\% of $\mathbf{n = 4 2 )}$} & \\
\hline $\mathbf{1} \mathbf{d}$ & $8(19)$ \\
\hline $\mathbf{1 - 7} \mathbf{d}$ & $15(36)$ \\
\hline $\mathbf{7} \mathbf{d}$ & $7(17)$ \\
\hline Unknown & $12(28)$ \\
\hline SE detection, no. of patients (\% of $\mathbf{n}=\mathbf{4 2})$ & \\
\hline Clinical & $28(67)$ \\
\hline EEG once & $4(10)$ \\
\hline EEG several times & $28(67)$ \\
\hline EEG monitoring & $10(23)$ \\
\hline
\end{tabular}

\section{Therapy SE, no. of antiepileptic drugs (AEDs) used} (\% of $n=42)$

\begin{tabular}{|c|c|}
\hline AED, median no. of different AEDs & 5 \\
\hline AED $\leq 4$, no. of patients $(\%)$ & $21(50)$ \\
\hline AED > 4, no. of patients (\%) & $21(50)$ \\
\hline Movement disorders, no. of patients (\% of $n=120$ ) & $39(33)$ \\
\hline \multicolumn{2}{|l|}{ Manifestation $(\%$ of $n=39)$} \\
\hline Generalized & $13(39)$ \\
\hline Focal & $23(58)$ \\
\hline Others $^{a}$ & $22(56)$ \\
\hline Complications of movement disorders & $11(28)$ \\
\hline \multicolumn{2}{|l|}{ Therapy movement disorders ( $\%$ of $n=39$ ) } \\
\hline Benzodiazepines & $29(74)$ \\
\hline AED & $21(53)$ \\
\hline Isoflurane & $2(5)$ \\
\hline Propofol & $12(31)$ \\
\hline Others $^{b}$ & $14(36)$ \\
\hline Other complications, no. of patients (\% of $n=120$ ) & $63(53)$ \\
\hline Severe sepsis & $31(26)$ \\
\hline Septic shock & $8(7)$ \\
\hline Cardiopulmonary resuscitation & $12(10)$ \\
\hline Surgical complications & $7(6)$ \\
\hline Venous thrombosis & $10(8)$ \\
\hline Others $^{c}$ & $49(42)$ \\
\hline
\end{tabular}

a Bruxism and axial rigor.

${ }^{\mathrm{b}}$ Opioids, atypical neuroleptics, and L-dopa.

c Pneumothorax, ICU-acquired weakness, self-injury, pleural effusions, suicide attempt, pulmonary embolism, rhabdomyolysis, allergic reaction, ileus, catheter infection, transfusion-dependent anemia, and severe electrolyte derangement.
Table 3 ICU complications and outcome

\begin{tabular}{ll}
\hline Variable & All \\
$n=120$
\end{tabular}

Mechanical ventilation (MV), no. of patients 68 (57)

$(\%$ of $n=120$ )

Duration of MV, median, d (IQR)

$28(10-54)$

Minimum/maximum, $d$

$0 / 350$

Reasons for MV, no. of patients (\% of $n=68$ )

\begin{tabular}{ll}
\hline Consciousness disorder & $47(69)$ \\
\hline Respiratory insufficiency & $36(53)$ \\
\hline Missing protection reflexes & $29(34)$ \\
\hline Hypoventilation & $6(9)$ \\
\hline Pneumonia & $13(19)$ \\
\hline Others ${ }^{\text {a }}$ & $9(13)$ \\
\hline Intubation, no. of patients (\% of $\mathbf{n}=\mathbf{6 8})$ & $63(93)$ \\
\hline Reintubation & $25(37)$ \\
\hline Tracheal cannula (TC) & $46(68)$ \\
\hline Duration intubation to TC, median, $\mathbf{d}$ & 10 \\
\hline
\end{tabular}

Complications of MV, no. of patients (\% of $n=68)$

\begin{tabular}{ll}
\hline Pleura drainage & $5(7)$ \\
\hline Acute respiratory distress syndrome & $4(6)$ \\
\hline Ventilator-associated pneumonia & $37(54)$ \\
\hline Others $^{\mathbf{b}}$ & $19(28)$ \\
\hline Ethical consideration, no. of patients $(\%$ of $\mathbf{n}=\mathbf{1 2 0})$ & $21(18)$ \\
\hline Change of therapy target & $8(7)$ \\
\hline DNR/DNI & $2(2)$ \\
\hline Treatment discontinuation $^{\prime}$ & $2(2)$ \\
\hline Ethical counseling & $2(2)$ \\
\hline Others &
\end{tabular}

Outcome ICU stay, no. of patients (\% of $n=120)$

\begin{tabular}{ll}
\hline Transfer to regular hospital ward & $68(57)$ \\
\hline Transfer to neurointensive care rehabilitation & $46(38)$ \\
\hline Deceased & $9(7.5)$ \\
\hline Duration ICU stay, median, d (IQR) & $24(7-45)$ \\
\hline Minimum/maximum, d & $1 / 400$ \\
\hline Duration hospital stay, median, d (IQR) & $49(31 / 100)$ \\
\hline Minimum/maximum, d & $1 / 1978$ \\
\hline
\end{tabular}

Abbreviations: $\mathrm{DNR}=$ do-not-resuscitate order; $\mathrm{DNI}=$ do-not-intubate order; $\mathrm{IQR}=$ interquartile range.

a Sedation in psychosis, status epilepticus, and severe sepsis.

${ }^{b}$ Recurrent pneumonia, difficult airway, severe sepsis, intubation injury, and pneumothorax.

'Dismissal against medical advice, personal risk, and extraneous endangering. 
Figure Alluvial plot of modified Rankin Scale (mRS) scores during and at the end of hospital stay

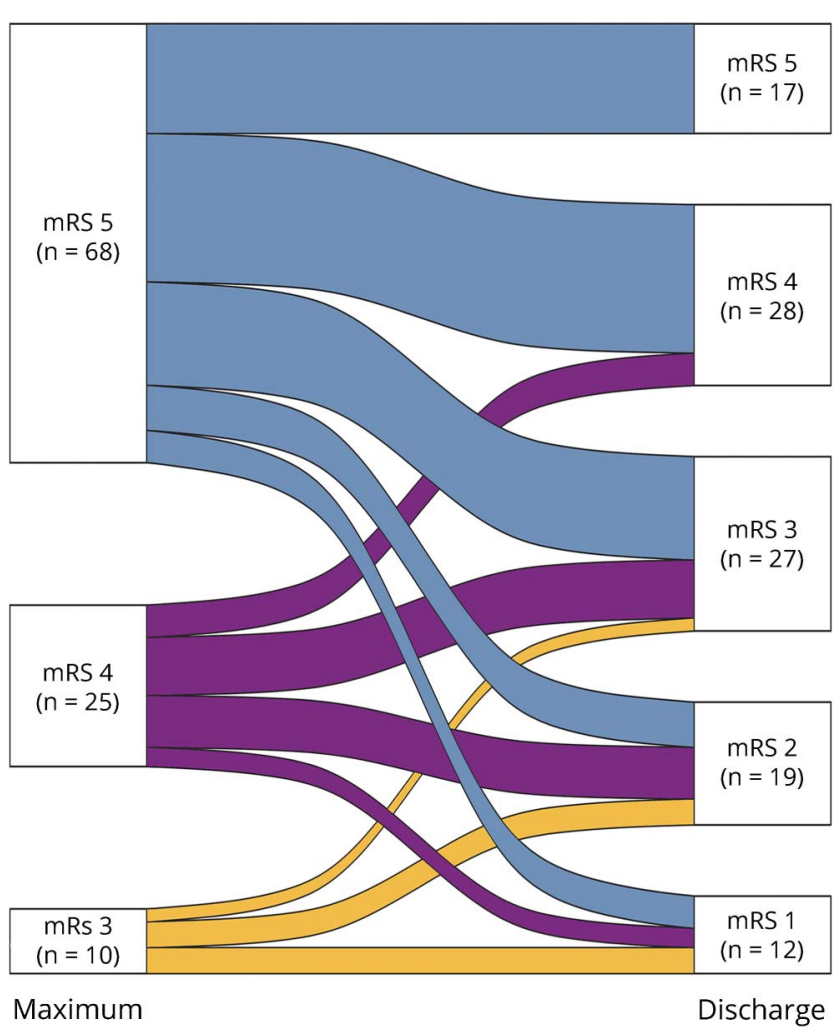

Left: mRS scores 3-5 at maximum mRS during hospitalization, right: mRS scores 1-5 at hospital discharge. The alluvial plot shows the number of patients crossing over from the maximum mRS score during hospitalization to the final mRS score at discharge. In all 3 "maximum" groups, the transition goes downward at a percentage of $\geq 75 \%$. The height of a mRS block represents the size of the group, and the height of a stream field represents the size of the components contained in both blocks connected by the stream field. Deceased patients (mRS 6) are not included in the figure There were no patients with mRS 0-2 at disease maximum.

prognostic factors, the presence of autonomic dysfunction (OR 2.9), severe sepsis/septic shock (OR 4.5), tracheostomy (OR 6.3), a tumor finding (OR 3.7), and the need for mechanical ventilation (OR 6.3) in addition to its duration (OR per each day 1.03) were all associated with a poor neurologic outcome at hospital discharge. In contrast, we observed no correlation for a correlation of prodromal symptoms, status epilepticus, ethical considerations, diagnostic results such as pathologic brain imaging (MRI and PET), pathologic EEG, or antibody status with the dichotomized neurologic outcome at hospital discharge.

\section{Discussion}

The findings of our study provide a number of relevant insights regarding prognostic factors for outcome in severely affected patients with AE. These insights may increase awareness of the potential poor prognostic factors in patients with $\mathrm{AE}$ requiring ICU treatment.

First, autonomic dysfunction, associated with worse outcome, is critical in a major subset of patients. It is an intrinsic aspect of $\mathrm{AE}$, particularly NMDA receptor encephalitis (RE), which represents the largest patient group within our cohort. ${ }^{5,7,10,11}$ Thus, autonomic dysfunction can be regarded as being a disease-specific risk factor or indicator for poor outcome. It can be hypothesized to be a causative trigger factor for further intensive care-associated complications, e.g., hypotension requiring vasopressors or respiratory dysfunction requiring mechanical ventilation resulting in ventilatorassociated pneumonia.

Second, similar to ICU patients with diseases other than AE, severe sepsis and septic shock were strongly related to worse neurologic outcome. ${ }^{12}$ Of interest, the proportion of patients who developed severe sepsis and septic shock that resulted in organ dysfunction (33\%) was more than doubled in patients with severe $\mathrm{AE}$ compared with the general ICU population in Germany with a rate of $13 \%$ in 1 study. ${ }^{13}$ Treatment-induced immunosuppression, autonomic dysfunction, and a longer duration of mechanical ventilation most likely contributed to the increased proportion of sepsis and sepsis-induced organ dysfunction in our cohort.

Third, paraneoplastic origin (teratoma and other tumors in 21\% of patients) was strongly associated with worse outcome as measured by the dichotomized $\mathrm{mRS}$ score. This is in accordance with previous reports focusing on NMDA-RE. Here, tumor removal led to faster improvement and fewer relapses. ${ }^{5,14}$

In addition to the aforementioned disease-related factors, prolonged mechanical ventilation is associated with worse outcome. Here, similar results have been reported in acute encephalitis of all etiologies. ${ }^{2,15}$ A number of conditions are associated with the need for long-term respiratory support in this severely affected patient cohort including the increased risk of infection and pneumonia due to immunosuppression and the development of ICU-acquired weakness, which frequently affects critically ill patients and contributes to worse acute outcome and long-term mortality. ${ }^{16}$ Surprisingly, status epilepticus was not associated with a deterioration of neurologic outcome, although it was detected in a relevant subset of 35\% of all patients. However, there was a slight tendency wherein pathologic EEG findings to be more frequently associated with a worse outcome. In clinical practice, seizure-related myoclonic activity may be difficult to differentiate from dyskinetic and stereotypic movements associated with certain $\mathrm{AE}$ subtypes. Therefore, the rate of status epilepticus in these patients may be overestimated, leading to decreased specificity in the evaluation of this factor in correlation with clinical outcome.

Paraclinical findings, e.g., pleocytosis and increased CSF protein levels, abnormal cerebral MRI, or FDG-PET are helpful for the diagnostic workup ${ }^{17}$ but are apparently not relevant for evaluating the risk of poor clinical outcome after ICU therapy. Although antineuronal autoantibodies were detected in 85 patients (71\%), mostly NMDA-R antibodies (in 53 patients), these findings did not predict a negative or a positive neurologic outcome. This result is of relevance to 
Table 4 Potential prognostic factors of the neurologic outcome at hospital discharge according to the dichotomized modified Rankin Scale (mRS)

\begin{tabular}{|c|c|c|c|c|c|}
\hline & Potential prognostic factor & Crude OR $(95 \% \mathrm{CI})$ & $p$-value (2-sided) & Adjusted OR $(95 \% \mathrm{Cl})$ & $p$-value (2-sided) \\
\hline S & Prodromal symptoms [absent] & $1.03(0.44-2.41)$ & 0.95 & $1.28(0.52-3.19)$ & 0.59 \\
\hline $\mathbf{Y}$ & Consciousness disorder [absent] & $1.80(0.63-5.57)$ & 0.28 & $2.39(0.8-7.84)$ & 0.13 \\
\hline M & Somnolence [absent] & $1.41(0.64-3.09)$ & 0.39 & $1.36(0.61-3.05)$ & 0.45 \\
\hline $\mathbf{P}$ & Autonomic dysfunction [absent] & $1.69(0.8-3.59)$ & 0.17 & $2.91(1.24-7.3)$ & 0.02 \\
\hline $\mathbf{T}$ & Status epilepticus [absent] & $0.90(0.42-1.92)$ & 0.78 & $0.95(0.43-2.09)$ & 0.91 \\
\hline 0 & Other complications [absent] & $4.21(1.95-9.42)$ & $3.3 \times 10^{-4}$ & $4.45(1.99-10.43)$ & $3.9 \times 10^{-4}$ \\
\hline M & Sepsis/septic shock [absent] & $3.97(1.67-10.11)$ & $2.4 \times 10^{-3}$ & $4.54(1.84-12.11)$ & $1.5 \times 10^{-3}$ \\
\hline w & Pathologic CSF [absent] & $0.76(0.21-2.71)$ & 0.67 & $0.94(0.25-3.5)$ & 0.92 \\
\hline 0 & Pathologic MRI brain imaging [absent] & $0.91(0.41-2.03)$ & 0.82 & $0.79(0.34-1.81)$ & 0.57 \\
\hline $\mathbf{R}$ & Pathologic EEG [absent] & $0.35(0.12-0.90)$ & 0.04 & $0.40(0.14-1.09)$ & 0.08 \\
\hline $\mathbf{K}$ & Pathologic PET brain imaging [absent] & $0.76(0.32-1.73)$ & 0.51 & $0.53(0.21-1.28)$ & 0.17 \\
\hline u & Tumor [absent] & $3.82(1.43-11.49)$ & 0.01 & $3.73(1.35-11.57)$ & 0.01 \\
\hline \multirow[t]{3}{*}{$\mathbf{P}$} & Autoantibody [absent] & $0.84(0.38-1.85)$ & 0.66 & $1.01(0.44-2.33)$ & 0.98 \\
\hline & Autoantibody in CSF [absent] & $1.11(0.53-2.35)$ & 0.78 & $1.46(0.66-3.31)$ & 0.35 \\
\hline & Autoantibody in serum [absent] & $0.78(0.37-1.66)$ & 0.53 & $0.90(0.41-1.98)$ & 0.80 \\
\hline $\mathbf{T}$ & Mechanical ventilation [absent] & $5.78(2.60-13.61)$ & $3.0 \times 10^{-5}$ & $6.28(2.71-15.61)$ & $3.5 \times 10^{-5}$ \\
\hline H & Duration of ventilation [days] & $1.03(1.02-1.05)$ & $3.8 \times 10^{-4}$ & $1.03(1.02-1.06)$ & $2.1 \times 10^{-4}$ \\
\hline $\mathbf{E}$ & Tracheostomy [absent] & $4.98(2.24-11.57)$ & $1.2 \times 10^{-4}$ & $6.26(2.68-15.73)$ & $4.5 \times 10^{-5}$ \\
\hline $\mathbf{R}$ & Ethical considerations [absent] & $1.3(0.48-3.55)$ & 0.61 & $1.52(0.54-4.39)$ & 0.43 \\
\hline
\end{tabular}

Effect size estimates (with $95 \% \mathrm{Cl}$ ) are provided such that ORs > 1 indicate a correlation with a worse outcome (usually with the presence of a pathologic finding). The reference category or unit is provided in square brackets. Adjusted ORs were adjusted only for sex and age (linear) because of the limited number of patients. Left column: SYMPTOM-main symptoms and ICU complications; WORKUP—diagnostic findings; THER-therapeutic management and ethical considerations.

clinical-based decision in contrast to relying on the diagnostic test for antineuronal autoantibodies because there are still a number of antibodies that cannot be reliably detected using the available laboratory tests. ${ }^{18}$

Disorders of consciousness such as delirium have recently been identified as a risk factor for developing long-term cognitive dysfunction after surviving sepsis in a large cohort of ICU patients. ${ }^{19}$ Our data showed no evidence for an association of altered consciousness with regard to the short-term outcome in our study. However, neurocognitive dysfunction is a major factor influencing the overall condition and is highly relevant for patients for managing their daily activities, it is therefore also relevant for evaluating in the patients' mRS scores. The study design did not include a regular neuropsychological assessment at hospital discharge and no follow-up evaluation of patients. Because most patients exhibited mRS scores above 3, for which cognitive dysfunction is less significant, the relevance of consciousness disorders on overall outcome may be underestimated. It would be interesting to conduct a future study evaluating neurocognitive dysfunction in either this or a similar patient cohort as a long-term follow-up similar to what has already been undertaken in NMDA-RE-cohorts. ${ }^{20}$

Our patients showed severe deficits: $90 \%$ of patients had a maximum mRS score 4-6 during their disease course. At the time of ICU discharge, however, this improved remarkably in $75 \%$ of the surviving patients, with only $48 \%$ of patients showing an mRS value of $\geq 4$ ( $28 \% \mathrm{mRS} 4$ and $15 \% \mathrm{mRS} 5)$. The hospital mortality rate of $7.5 \%$ in our cohort was almost identical with the recently published ICU NMDA-RE study. ${ }^{7}$ However, in other cohorts with $\mathrm{AE}$, the reported mortality was much higher. ${ }^{2,21-23}$ The reasons for this low mortality might be the improved treatment and earlier recognition and diagnosis of AE. In addition, there might also be a bias attributable to the fact that relatives/spouses of deceased patients refused their informed consent.

Neuro-ICU management in patients with $\mathrm{AE}$ frequently involves a long period of care. Therefore, complications, sometimes severe, occur in a majority of patients. More detailed knowledge of the individual prognosis based on well- 
defined risk factors will aid decision making by both physicians and family members/spouses with regard to ICU treatment in supposedly treatment-resistant cases. Consequently, ethical decisions will have to be addressed. For example, 10 women underwent ovarectomy and were confronted with a lifelong challenge regarding family planning after surviving their acute illness. The discussion on the necessity of explorative or even prophylactic ovarectomy has increased recently as evidenced in 2 case reports of postencephalitic ovary removal 1 year after initial NMDA-RE in adolescent patients without symptoms. ${ }^{24}$ Issues resulting in lifelong consequences for patients need to be further addressed, in particular, because data, for example, on tumor incidence in different age groups ${ }^{11}$ and ethnicities ${ }^{10}$ show differential results.

Our analysis was performed using retrospectively collected patient data obtained from a subgroup of 120 patients who required IUC treatment. These patients were revealed from a nationwide cohort in Germany, which in the meantime consists of more than 750 patients with AE (GENERATE cohort; generate-net.de/). To our knowledge, this cohort of 120 patients represents the largest reported cohort of critically ill patients with $\mathrm{AE}$ who underwent ICU treatment compared with previous studies with patients with $\mathrm{AE}^{3,4,7,21,22}$ and mixed encephalitis cohorts including AE subgroups. ${ }^{2,15,25,26}$

This notwithstanding, some limitations need to be discussed herein:

First, the study is a noninterventional retrospective analysis and therefore not suitable for detecting cause and effect relationships.

Second, patients with a date of disease onset between 2004 and 2016 were enrolled in the study. During this time, awareness of AEs and antibody testing increased, reducing the time to treatment. Furthermore, while planning the study, the inclusion criteria were based on the encephalitis criteria as published by Granerod et al. ${ }^{1}$ Since then, the Graus criteria have been published in February 2016. ${ }^{8}$ According to the Graus criteria, the 35 patients without evidence of autoantibody in CSF or serum have been considered as possible $\mathrm{AE}$ rather than definite $\mathrm{AE}$. Although, from a clinical standpoint, it still seems reasonable to include these patients in our cohort, although they were antibody negative. In addition, ICU management probably remained relatively unchanged. The continuing analysis of the present cohort will focus on the influence of (German) guidelines on $\mathrm{AE}$ management. ${ }^{27}$

Third, the 120 cases included in our study did not allow for a more profound analysis of rare or less frequent potential prognostic factors. Note that the statistical power for 120 patients is rather limited. Therefore, further adjustments or multiple testing corrections were not applied. In addition, a documentation bias should be mentioned. Clearly, extended clinical interpretations of our findings could only be justified on the basis of their confirmation in an independent dataset.
Finally, the primary end point focused on outcome data at "hospital discharge" because it was not possible to obtain follow-up data of the patients, which might provide further important information, e.g., on long-term cognitive function.

Ultimately, our aim is that the data gathered within the tight network and close cooperation will provide evidence-based support with regard to ICU management and may be of advantage for counseling patients and relatives during a severe and threatening course of an autoimmune disease according to the relevant influencing factors.

The spectrum of ICU complications and the severity of the underlying disease reflect some general ICU- and specific AErelated features. Of interest, and despite early targeted immunotherapy, ${ }^{7}$ clinically highly threatening courses of AE still occur. Focusing on the earliest possible clinical diagnosis according to the Graus criteria ${ }^{8}$ may foster earlier immunotherapy. Moreover, these critical disease courses underscore the need for novel, target-specific treatment approaches beyond immunotherapy. Future studies should reveal whether such clinical rather than diagnostic-based approaches will result in less ICU complications in patients with AE. Cooperation and dialogue within a network such as GENERATE and IGNITE might be beneficial to AE-related ICU treatment because they could lead to an interdisciplinary evaluation of earlier and if necessary more aggressive management of $\mathrm{AE}$ resulting in better short- and long-term outcomes.

\section{Acknowledgment}

The authors thank Nasim Kroegel for language editing and Dr. Theresa Götz for support regarding data visualizations.

\section{Study funding}

André Scherag and the "Center for Sepsis Control and Care" were funded by the German Ministry of Education and Research (Bundesministerium für Bildung und Forschung Grants 01EO1002 and 01EO1502).

\section{Disclosure}

J. Schubert and D. Braemer report no disclosures. H.B. Huttner received advisory board fees from Boehringer Ingelheim and Medtronic; received travel funding from Boehringer Ingelheim; and received research support from the German Research Foundation. S.T. Gerner reports no disclosures. H. Fuhrer received commercial travel funding. N. Melzer served on the commercial advisory board of Alexion; received travel funding and/or speaker honoraria from Biogen, GlaxoSmithKline, Teva, Fresenius, and Alexion; performs immunoadsorption about $5 \%$ of their time; and received research support from Fresenius Medical Care, Diamed, and Novartis. A. Dik, H. Pruess, L.-T. Ly, and K. Fuchs report no disclosures. F. Leypoldt served on the scientific advisory boards of Roche and Biogen; received travel funding and/or speaker honoraria from Grifols, Teva, Biogen, Fresenius, Bayer, and Merck; and performs commercial antibody testing service about $20 \%$ of their time. G. Nissen reports no disclosures. I. Schirotzek 
served on the scientific advisory boards of Merck Serono, Sanofi-Aventis, and BARD and received travel funding and/or speaker honoraria from Merck Serono, Sanofi-Aventis, Teva, Biogen, Novartis, and Roche. C. Dohmen reports no disclosures. J. Bosel received travel funding and speaker honoraria from Bard, Zoll, Sedana Medical, Medtronic, and Boehringer Ingelheim; served on the editorial boards of Neurocritical Care and Neurology Research and Practice; receives publishing royalties from Thieme; and received research support from DGNI. J. Lewerenz received speaker honoraria and/or travel funding from Euroimmun, Teva, CHDI, and Movement Disorders Society and oversees a laboratory of a nonprofit hospital that offers testing for antineuronal and onconeuronal antibodies. F. Thaler, A. Kraft, and A. Juranek report no disclosures. M. Ringelstein received travel funding and/or speaker honoraria from Novartis, Ipsen, Bayer, Biogen, Genzyme, Teva, Merz, and Merck. K.-W. Suehs served on the scientific advisory board of Merck and received travel funding from Merck. C. Urbanek and A. Scherag report no disclosures. C. Geis received travel funding from Merck Serono; served as a guest editor of Frontiers Neurology; and received research support from the German Research Council and the German Ministry of Education. O.W. Witte served on the editorial boards of Das Neurophysiologie-Labor and Zeitschrift für klinische Neurophysiologie and received research support from the German Research Foundation, Thuringian Ministry for Education, Science and Culture, Federal Ministry for Research and Technology, and European Union. E. Kroner reports no disclosures. A. Guenther received travel funding and/or speaker honoraria from Merz, Ipsen, Boehringer Ingelheim, Pfizer, Daiichi Sankyo, and Bayer. Full disclosure form information provided by the authors is available with the full text of this article at Neurology.org/NN.

Received June 19, 2018. Accepted in final form September 17, 2018.

Appendix 1 Author contributions

\begin{tabular}{|c|c|c|c|}
\hline Name & Location & Role & Contribution \\
\hline Julia Schubert, MD & University of Jena, Jena, Germany & Author & $\begin{array}{l}\text { Designed and conceptualized the study; analyzed the data; } \\
\text { and drafted the manuscript for intellectual content }\end{array}$ \\
\hline Dirk Brämer, MD & University of Jena, Jena, Germany & Author & $\begin{array}{l}\text { Designed and conceptualized the study; analyzed the data; } \\
\text { and drafted the manuscript for intellectual content }\end{array}$ \\
\hline Hagen B. Huttner, MD & University of Erlangen, Erlangen, Germany & Author & $\begin{array}{l}\text { Major role in the acquisition of data and interpretation of } \\
\text { data and revised the manuscript for intellectual content }\end{array}$ \\
\hline Stefan T. Gerner, MD & University of Erlangen, Erlangen, Germany & Author & $\begin{array}{l}\text { Major role in the acquisition of data and interpretation of } \\
\text { data and revised the manuscript for intellectual content }\end{array}$ \\
\hline Hannah Fuhrer, MD & University of Freiburg, Freiburg, Germany & Author & $\begin{array}{l}\text { Major role in the acquisition of data and interpretation of } \\
\text { data }\end{array}$ \\
\hline Nico Melzer, MD & University of Münster, Münster, Germany & Author & $\begin{array}{l}\text { Major role in the acquisition of data and interpretation of } \\
\text { data and revised the manuscript for intellectual content }\end{array}$ \\
\hline André Dik, MD & University of Münster, Münster, Germany & Author & Major role in the acquisition of data \\
\hline Harald Prüss, MD & Charité University Medicine, Berlin, Germany & Author & $\begin{array}{l}\text { Major role in the acquisition of data and interpretation of } \\
\text { data }\end{array}$ \\
\hline Lam-Than Ly, MD & Charité University Medicine, Berlin, Germany & Author & $\begin{array}{l}\text { Major role in the acquisition of data and interpretation of } \\
\text { data }\end{array}$ \\
\hline Kornelius Fuchs, MD & University of Regensburg, Germany & Author & $\begin{array}{l}\text { Major role in the acquisition of data and interpretation of } \\
\text { data }\end{array}$ \\
\hline Frank Leypoldt, MD & $\begin{array}{l}\text { University of Schleswig-Holstein, Kiel, } \\
\text { Germany }\end{array}$ & Author & $\begin{array}{l}\text { Major role in the acquisition of data and interpretation of } \\
\text { data and revised the manuscript for intellectual content }\end{array}$ \\
\hline Gunnar Nissen, MD & $\begin{array}{l}\text { University of Schleswig-Holstein, Kiel, } \\
\text { Germany }\end{array}$ & Author & Major role in the acquisition of data \\
\hline Ingo Schirotzek, MD & University of Giessen, Giessen, Germany & Author & Major role in the acquisition of data \\
\hline Christian Dohmen, MD & University of Cologne, Cologne, Germany & Author & Major role in the acquisition of data \\
\hline Julian Bösel, MD & $\begin{array}{l}\text { University of Heidelberg, Heidelberg, } \\
\text { Germany }\end{array}$ & Author & Major role in the acquisition of data \\
\hline Jan Lewerenz, MD & University of Ulm, Ulm, Germany & Author & $\begin{array}{l}\text { Major role in the acquisition of data and interpretation of } \\
\text { data and revised the manuscript for intellectual content }\end{array}$ \\
\hline Franziska Thaler, MD & University of Munich, Munich, Germany & Author & Major role in the acquisition of data \\
\hline
\end{tabular}




\begin{tabular}{|c|c|c|c|}
\hline Name & Location & Role & Contribution \\
\hline Andrea Kraft, MD & Martha Maria Hospital, Halle, Germany & Author & Major role in the acquisition of data \\
\hline Aleksandra Juranek, MD & Dortmund Hospital, Dortmund, Germany & Author & Major role in the acquisition of data \\
\hline Marius Ringelstein, MD & University of Düsseldorf & Author & Major role in the acquisition of data \\
\hline Kurt-Wolfram Sühs, MD & University of Hannover, Hannover, Germany & Author & Major role in the acquisition of data \\
\hline Christian Urbanek, MD & $\begin{array}{l}\text { Hospital Ludwigshafen, Ludwigshafen, } \\
\text { Germany }\end{array}$ & Author & Major role in the acquisition of data \\
\hline André Scherag, PhD & University of Jena, Jena, Germany & Author & $\begin{array}{l}\text { Planned and performed biostatistical analyses and } \\
\text { interpretation of data and revised the manuscript for } \\
\text { intellectual content }\end{array}$ \\
\hline Christian Geis, MD & University of Jena, Jena, Germany & Author & $\begin{array}{l}\text { Major role in the acquisition of data and revised the } \\
\text { manuscript for intellectual content }\end{array}$ \\
\hline Otto W. Witte, MD & University of Jena, Jena, Germany & Author & $\begin{array}{l}\text { Designed and conceptualized the study and revised the } \\
\text { manuscript for intellectual content }\end{array}$ \\
\hline Albrecht Günther, MD & University of Jena, Jena, Germany & Author & $\begin{array}{l}\text { Designed and conceptualized the study, performed } \\
\text { acquisition of data, analyzed the data, and drafted the } \\
\text { manuscript for intellectual content }\end{array}$ \\
\hline
\end{tabular}

\section{References}

1. Granerod J, Ambrose HE, Davies NWS, et al. Causes of encephalitis and differences in their clinical presentations in England: a multicenter, populations-based prospective study. Lancet Infect Dis 2010;10:835-844.

2. Singh TD, Fugate JE, Rabinstein AA. The spectrum of acute encephalitis: causes, management, and predictors of outcome. Neurology 2015;84:359-366.

3. Davies G, Irani SR, Coltart C, et al. Anti-N-methyl-D-aspartate receptor antibodies: a potentially treatable cause of encephalitis in the intensive care unit. Crit Care Med 2010;38:679-682.

4. Mittal MK, Rabinstein AA, Hocker SE, Pittock SJ, Wijdicks EFM, McKeon A. Autoimmune encephalitis in the ICU: analysis of phenotypes, serologic findings, and outcomes. Neurocrit Care 2016;24:240-250.

5. Titulaer MJ, McCracken L, Gabilondo I, et al. Treatment and prognostic factors for long-term outcome in patients with anti-NMDA receptor encephalitis: an observational cohort study. Lancet Neurol 2013;12:157-165.

6. Prüss H, Dalmau J, Harms L, et al. Retrospective analysis of NMDA receptor antibodies in encephalitis of unknown origin. Neurology 2010;75:1735-1739.

7. de Montmollin E, Demeret S, Brulé N, et al. Anti-N-methyl-D-aspartate receptor encephalitis in adult patients requiring intensive care. Am J Respir Crit Care Med 2017;195:491-499.

8. Graus F, Titulaer MJ, Balu R, et al. A clinical approach to diagnosis of autoimmune encephalitis. Lancet Neurol 2015;15:391-404.

9. van Swieten JC, Koudstaal PJ, Visser MC, et al. Interobserver agreement for the assessment of handicap in stroke patients. Stroke 1988;9:604-607.

10. Dalmau J, Lancaster E, Martinez-Hernandez E, Rosenfeld MR, Balice-Gordon R. Clinical experience and laboratory investigations in patients with anti-NMDAR en cephalitis. Lancet Neurol 2011;10:63-74.

11. Titulaer MJ, McCracken L, Gabilondo I, et al. Late-onset anti-NMDA receptor encephalitis. Neurology 2013;81:1058-1063.

12. Vincent JL, Sakr Y, Sprung CL, et al. Sepsis in European intensive care units: results of the SOAP study. Crit Care Med 2006;34:344-353.

13. SepNet Critical Care trials Group. Incidence of severe sepsis and septic shock in German intensive care units: the prospective, multicentre INSEP study. Intensive Care Med 2016;42:1980-1989.
14. Dalmau J, Gleichman AJ, Hughes EG, et al. Anti-NMDA-receptor encephalitis: case series and analysis of the effects of antibodies. Lancet Neurol 2008; 1091-1098.

15. Thakur KT, Motta M, Asemota AO, et al. Predictors of outcome in acute encephalitis. Neurology 2013;81:793-800.

16. Hermans G, Van den Berghe G. Clinical review: intensive care acquired weakness. Crit Care 2015;19:274.

17. Tripathi M, Tripathi M, Roy SG, et al. Metabolic topography of autoimmune nonparaneoplastic encephalitis. Neuroradiology 2018;60:189-198.

18. Dalmau J, Geis C, Graus F. Autoantibodies to synaptic receptors and neuronal cell surface proteins in autoimmune diseases of the central nervous system. Physiol Rev 2017;97:839-887.

19. Iwashyna TJ, Ely EW, Smith DM, Langa KM. Long-term cognitive impairment and functional disability among survivors of severe sepsis. JAMA 2010;304: 1787-1794.

20. Finke C, Kopp U, Prüss $\mathrm{H}$, et al. Cognitive deficits following anti-NMDA receptor encephalitis. J Neurol Neurosurg Psychiatry 2012;83:195-198.

21. Harutyunyan G, Hauer L, Dünser MW, et al. Autoimmune encephalitis at the neurological intensive care unit: etiologies, reasons for admission and survival. Neurocrit Care 2017;27:82-89.

22. Harutyunyan G, Hauer L, Dünser MW, et al. Risk factors for intensive care unit admission in patients with autoimmune encephalitis. Front Immunol 2017;8:835.

23. Chi $\mathrm{X}$, Wang $\mathrm{W}$, Huang $\mathrm{C}$, et al. Risk factors for mortality in patients with anti-NMDA receptor encephalitis. Acta Neurol Scand 2017;136:298-304.

24. Omata T, Kodama K, Watanabe Y, et al. Ovarian teratoma development after antiNMDA receptor encephalitis treatment. Brain Dev 2017;39:448-451.

25. Chen X, Li JM, Liu F, Wang Q, Zhou D, Lai X. Anti-N-methyl-D-aspartate receptor encephalitis: a common cause of encephalitis in the intensive care unit. Neurol Sci 2016;37:1993-1998.

26. Sonneville R, Gault N, de Montmollin E, et al. Clinical spectrum and outcomes of patients with encephalitis requiring intensive care. Eur J Neurol 2015;22:6-16.

27. Bien CG, Rüegg S, Schmutzhard E, et al. Immunvermittelte Erkrankungen der grauen ZNSSubstanz sowie Neurosarkoidose. In: Diener HC, Putzki N, editors. (Hrsg) Leitlinien für Diagnostik und Therapie in der Neurologie. Georg Thieme. Stuttgart; 2012:476-548. 


\title{
Neurology \\ Neuroimmunology \& Neuroinflammation
}

\author{
Management and prognostic markers in patients with autoimmune encephalitis \\ requiring ICU treatment \\ Julia Schubert, Dirk Brämer, Hagen B. Huttner, et al. \\ Neurol Neuroimmunol Neuroinflamm 2019;6; \\ DOI 10.1212/NXI.0000000000000514
}

This information is current as of October 30, 2018

\section{Updated Information \& Services}

References

Subspecialty Collections

Permissions \& Licensing

Reprints including high resolution figures, can be found at: http://nn.neurology.org/content/6/1/e514.full.html

This article cites 26 articles, 1 of which you can access for free at: http://nn.neurology.org/content/6/1/e514.full.html\#\#ref-list-1

This article, along with others on similar topics, appears in the following collection(s):

Autoimmune diseases

http://nn.neurology.org//cgi/collection/autoimmune_diseases Critical care

http://nn.neurology.org//cgi/collection/critical_care

Encephalitis

http://nn.neurology.org//cgi/collection/encephalitis

Status epilepticus

http://nn.neurology.org//cgi/collection/status_epilepticus

Information about reproducing this article in parts (figures,tables) or in its entirety can be found online at:

http://nn.neurology.org/misc/about.xhtml\#permissions

Information about ordering reprints can be found online: http://nn.neurology.org/misc/addir.xhtml\#reprintsus

Neurol Neuroimmunol Neuroinflamm is an official journal of the American Academy of Neurology.

Published since April 2014, it is an open-access, online-only, continuous publication journal. Copyright Copyright $\odot 2018$ The Author(s). Published by Wolters Kluwer Health, Inc. on behalf of the American Academy of Neurology.. All rights reserved. Online ISSN: 2332-7812.

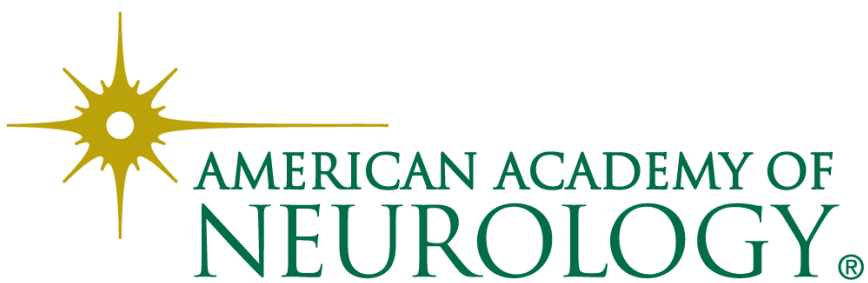

